\title{
DENGUE FEVER IN JEDDAH, SAUDI ARABIA: A COMPARISON BETWEEN ADULT AND PEDIATRIC INFECTIONS
}

\author{
By
}

OSAMA ELSAYED MOHAMED BEKHIT ${ }^{*}$, ABDULELAH ABDULGHANI ALFATANI ${ }^{2 \star}$, AMGAD HAMED KAMEL ${ }^{3}$ and MAHMOUD HAMDY REZK EID ${ }^{4}$

Department of Pediatrics, Faculty of Medicine, Fayoum University, Egypt ${ }^{1}$, Pediatrics Consultant, Ministry of Health, Saudi Arabia ${ }^{2}$, Department of Tropical Medicine, Faculty of Medicine, Ain Shams University ${ }^{3}$ and Department of Clinical Pathology, Laboratory Consultant Andalusia Hospital, Jeddah, Saudi Arabia ${ }^{4}$

( ${ }^{\star}$ Correspondence: dr_elsayed71@yahoo.com, \& **fatani97@hotmail.com)

\section{Abstract}

Dengue fever is a major infection in the world which geographically expanded. The disease is caused by dengue virus that transfers by Aedes mosquito mainly Ae. aegypti. It is endemic in Saudi Arabia and several outbreaks were reported. The virus primary affects different age groups. Dengue virus can cause classic dengue fever, dengue hemorrhagic fever and dengue shock syndrome. This study reviewed the clinical pictures, laboratory results and outcome of DF in adults and pediatrics. The retrospective descriptive study included 274 DF patients was conducted at Andalusia Hospital, Jeddah, Saudi Arabia over one year. Demographic data, clinical spectrum and laboratory investigations were recorded.

The results showed that pediatrics were 45/274 (16.4\%), while adults were 229 (83.6\%), males were more dominant than females $(30$ or $66.7 \%$ \& 169 or $73.8 \%$ ) in pediatrics and adults respectively. Headache myalgia, and retro-orbital pain were the main clinical pictures in adults $(\mathrm{p}<0.05)$, while vomiting and diarrhea were prevalent in pediatrics $(\mathrm{p}<0.05)$. Anemia, thrombocytopenia and elevated liver enzymes were significantly higher in adults than pediatrics $(p<0.05)$. Hospital stay and severe DF (DHF \& DSS) were significantly higher in adults than pediatrics $(\mathrm{p}<0.05)$.

Keywords: Saudi Arabia, Dengue fever, Adults, Pediatrics, Clinical pictures

\section{Introduction}

Dengue fever (DF) is caused by human arbovirus (Gamil et al, 2014), transmitted between them by a mosquito vector (Alwafi $e t$ al, 2013), mainly Aedes aegypti and Ae. albopictus (WHO, 2015). Apart from the Aedes vector, at least four well-documented mode of dengue virus transmission in health care setting via needle-stick injury (Abdel Motagaly et al, 2017), and one case by non-percutaneous exposure were reported (Chen and Wilson, 2004). Some asymptomatic blood donors have viremia levels sufficient to transmit dengue to recipients of blood components (Stramer et al, 2012).

In Batavia 1779, DF was first discovered and after one year, Philadelphia, USA was reported to be pandemic with DF (McCallum, 2008). The first isolation of DF virus (DENV-2 \& DENV-1) was in 1994 in Jeddah as an outbreak of 289 confirmed cases (Fakeeh and Zaki, 2001). Several DF out- breaks were reported in Jeddah and surrounding areas (Fakeeh and Zaki, 2003; Khan et al, 2008; Zaki et al, 2008; El-Badry et al, 2014). Dengue fever is prevalent in tropical areas affecting both adults and children (WHO, 2015), CDC reported that almost 100 million cases needed hospitalization every year and in more than 100 countries the mortality caused by DF reached 22000 deaths per year and many of them were children (Knowlton et al, 2009). 3350 DF cases were reported in 2009 in the Kingdom with a fatality rate of 4.6/1000 (Saudi Ministry of Health; 2010). The prevalence of DF was reported in one study as $0.1 \%$ as an unexpected rate (Memish et al, 2011), however three studies (Ayyub et al, 2006; Khan et al, 2008; Al-Azraqi et al, 2013) reported prevalence range of $31.7 \%$ to56.9\% among clinically suspected patients.

Diagnostic assays include ELISA and molecular biology techniques that allowed the 
early detection of the epidemic outbreaks (Durand et al, 2003). Combination of guided clinical examination and laboratory tests are essential to confirm diagnosis (Rodrigues et $a l$, 2005). The incubation period ranged from 3 to 14 days (Shahina et al, 2009). DF ranges from mild to severe presentation, where patients with mild presentation experience limited low fever, however in severe cases, patients can be presented with lifethreating dengue hemorrhagic fever DHF and dengue shock syndrome DSS (Guzman and Kouri, 2002; Alwafi et al, 2013). Fever, nausea, vomiting, headache, abdominal pain and musculo-skeletal pain were the commonest DF symptoms (Khormi and Kumar, 2012; Kholedi et al, 2012). Genetic disposition, age and immune status are risk factors for developing DHF (Alhaeli et al, 2016). The clinical symptoms of DF involve liver (Gulati and Maheshwari, 2007), liver is not the target organ, and however necrosis, inflammation and derangement in liver enzymes were observed (Kuo et al, 1992). The changes in liver associated to DF differ between adults and children as a result of the differences in physiology and anatomy of liver between children and adults (Ginsberg et al, 2002; Kittigul et al, 2007). Sometimes, there were unusual DF clinical pictures in both adults and children (Torres et al, 2000; Yamamoto et al, 2002). It seems that there are several differences in presentation and outcome between adults and children, so in this study we aimed to compare clinical outcome and complications between adults and children who had DF.

\section{Subjects and Methods}

This descriptive retrospective study in Andalusia hospital Jeddah, KSA involving patients diagnosed with dengue infection from December 2014 to December 2015. The protocol was approved by the Ethical Committee of the hospital. Clinical data were collected from medical records and laboratory results were retrieved from laboratory data base. Diagnosis of dengue infection was confirmed by positive nonstructural protein antigen and positive IGM. Patients were divided into two groups: adult ( $>15$ years) and children.

Patients with chronic underlying disorder or associated infection were excluded from the study. Clinical and laboratory criteria for DF diagnosis and classification of severity were WHO guided (Hanafusa et al, 2008).

Statistical analysis: Data was analyzed by Package of Social Science Software program, version 23 (Armonk, NY: IBM Corp.). Data was summarized as mean, standard deviation (SD), median and range for quantitative variables, frequency and percentage for qualitative ones. Comparison was performed using Mann Whitney test (non-parametric data) for quantitative variables and Chi square and Fisher's exact test for qualitative ones. $\mathrm{P}$ values less than or equal to 0.05 were considered significant.

\section{Results}

The study included 274 patients diagnosed with Dengue from Andalusia hospital Jeddah, KSA, during the period from December 2014 to December 2015. There were 45 $(16.4 \%)$ patients in pediatric age group with $\mathrm{M} \pm \mathrm{SD}$ age of $11.6 \pm 3.4$ years and range from 2.9 to 15.0 years, adults constituted 229/274 $(83.6 \%)$ of patients with ages were 21.3 to 77.6 year with average of $39.2 \pm 11.8$ years.

Children, $30(66.7 \%)$ were males \& 15 $(33.3 \%)$ females with ratio 2:1. Adults, 169 $(73.8 \%)$ were males \& 60 (26.2\%) female with ratio 2.8:1 (Tab. 1).

Anorexia, abdominal pain and headache were the main clinical picture in all patients. Headache, myalgia and retro-orbital pain were significantly higher in adults $(0.03$, $0.04 \& 0.01)$ respectively. Vomiting \& diarrhea were significantly higher in children (0.01 \& 0.04) respectively (Tab. 2 ).

Adults had a significantly lower median platelet count and a higher hemoglobin level. Low significant difference was detected in white cell count between both. Follow up cases showed no statistical difference in platelet count and white cell count between both as hemoglobin level still significantly 
higher in adults than children (Tab. 3)

ALT levels were significantly higher in adults [(33.0-110.0) with a median 55U/L] than pediatric group [(25.75-61.0) with median $36.5 \mathrm{U} / \mathrm{L}]$. AST levels in adults were higher [(36.0-129.0) with median 61U/L] than children [(40-72.0) with a median 45U/L] but without significant. Follow up results revealed decline of ALT level in adults [(34.75-101.5) with median 54.5U/L] and rise in ALT level in children [(29.25$71.5)$ with median $50 \mathrm{U} / \mathrm{L}]$ without signifi- cant difference were detected. The same observation was noted on AST level that declined in adults [(43.0-101.0) with median 57U/L] and rose in children [(32.25-88.5) with median $64.5 \mathrm{U} / 1$ ] but without significant difference between both groups (Tab. 4).

In adults hospital stay was significantly higher [(4-6) with median 4 days] than pediatrics [(2-3) with median 3 days]. Severe dengue, dengue hemorrhagic fever \& dengue shock syndrome were significantly higher in adults (p 0.049) (Tab. 5). Table 1: Sex characteristics of patients

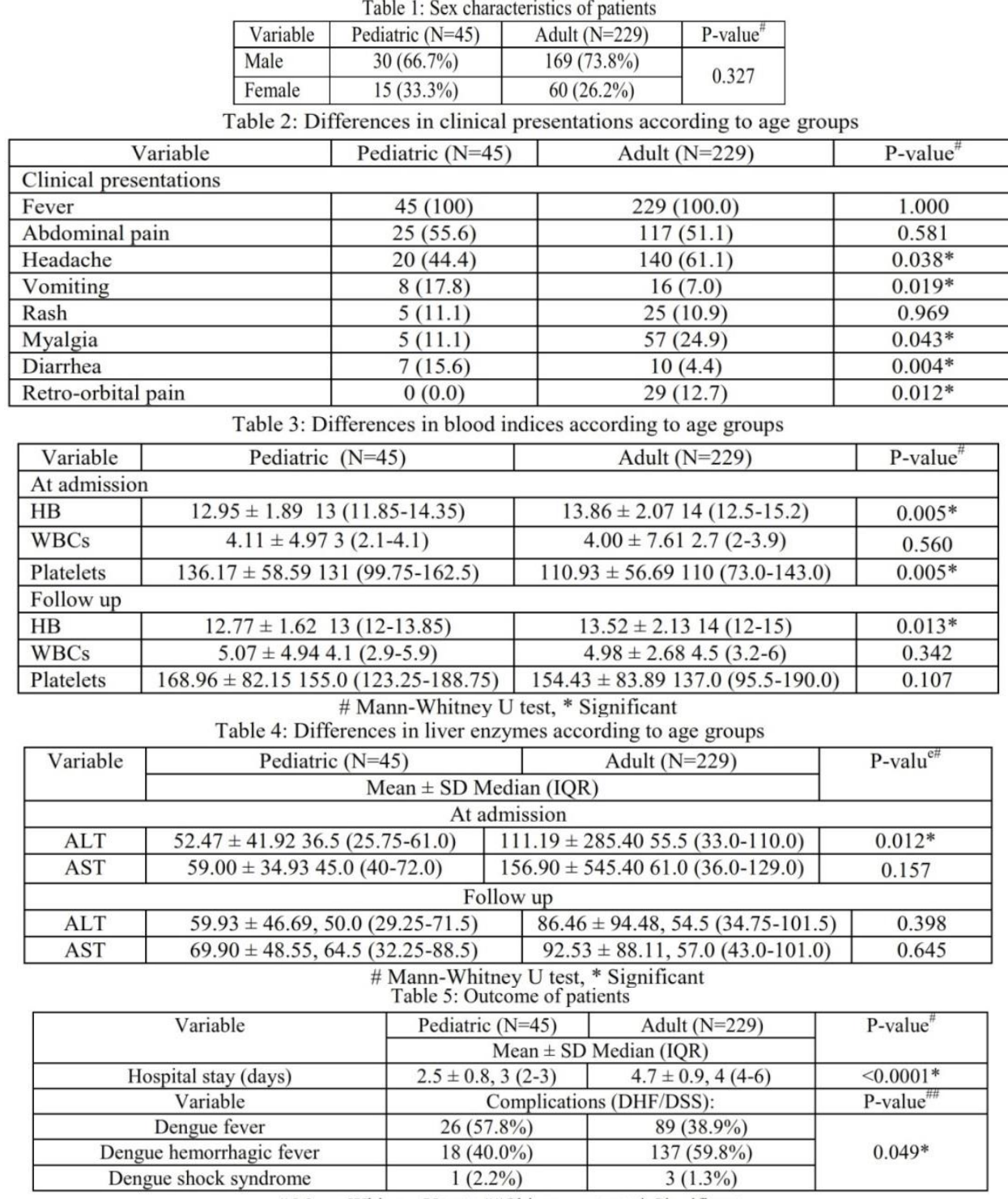

\# Mann-Whitney U test, \#\#Chi-square test, * Significant

\section{Discussion}

This retrospective study described dengue fever in children and adults in Jeddah City, which is one of highly infected area owing to huge number of visitors coming to pilg- rims (Haj and Omrah) and its climate conditions that favors dengue infection (Khormi and Kumar, 2012; Alhaeli et al, 2016).

In this study adults numbered children. This agreed with other studies carried out in 
KSA that explained the prevalence of DF in adults by being the age group that spends more outdoor time than children (Alwafi et al, 2013; Gamil et al, 2014) Other studies found higher prevalence of DF in children (Kulkarni et al, 2010; Souza et al, 2013) .

Although the difference was not significant, males were more affected more than females that was consistent to other Saudi studies as well as studies in France, Australia, Brazil and Mexico reporting higher DF incidence in them (Gutiérrez et al, 2013; Horta et al, 2014; Raza et al, 2014). Alwafi et al, 2013). The men are the main working power outdoor but women spend more time indoor, they wear covering clothes for religious purposes. Hence geographical distribution and culture could affect the epidemiology of DF. Fever was a cardinal manifestation in both groups. Abdominal pain was a common presenting symptom with no statistical difference between both groups. Studies reported abdominal pain as common DF presenting symptom (Kholedi et al, 2012; Sharmin et al, 2013). Headache, retro-orbital pain and myalgia were significantly higher in adults. This agreed with other studies that referred the prevalence of these manifestations in adults to difficult explanation of such symptoms by children and parents (Souza et al, 2013). Vomiting and diarrhea were significantly higher in children, these data were on line with other studies from Thailand and Philippines that reported higher gastrointestinal manifestations in children than adult (Namvongsa et al, 2013; Velasco et al, 2014). Skin rash was observed in few cases of patients that might be related to late admission when primary rash was abated.

Hemoglobin level was lower in children than adults in both initial evaluation of follow up investigation. This may be related to lower physiological values related to age. Platelet count was significantly lower in adults on initial investigation while no statistical difference was found on follow up. This agreed with others reported a more sever thrombocytopenia in adults than children destructing platelets and mega-karyocytes in bone marrow (Namvongsa et al, 2013).

Rise of aminotransferases (ALT, AST) was noted in both groups on admission. ALT was sig-nificantly higher in adults than children. Others reported more severe rise of ALT in adults than children. Hepatic involvement was referred to direct effect of virus on hepatocytes, deregulations of host immune response to virus. AST levels were higher than ALT levels in both groups. The higher AST levels referred to damage of myocytes at early stage of dengue infection (Wang et al, 2009; Martinez et al, 2016). Follow up showed aminotransferases decline in adults without concomitant decline in children. This might be due to risky effect of virus on children or use of hepatotoxic drugs as acetaminophen a commonly used analgesic and antipyretic in children.

Longer hospital stay and severe dengue in adults were significantly higher with distinctive serotypes (Souza et al, 2013). Others reported more severe dengue and longer hospital stay in children (Hammond et al, 2005; Namvongsa et al, 2013) referred these findings to secondary dengue infection, in contrary to the present study as primary infection caused protection against severe disease. Severe dengue is a relatively rare but its serious complication due to plasma leaking, fluid accumulation, respiratory distress, severe bleeding or organ impairment. Severe dengue may be life-threatening, but early diagnosis and prompt therapy decreased fatality to far below 1\% (WHO, 2017).

Dengue may be resurging in the Middle East and North Africa (WHO, 2014) with unprecedented outbreaks or previously unrecognized magnitude occurred in Pakistan (Rai, 2011), the Arabian Peninsula (Arya and Agarwal, 2014) and an outbreak in Egypt occurred following a decades-long absence of reported cases from that country (WHO, 2015). Still, despite increasing global concern about the threat of Aedes-transmission, dengue epidemiology in the MENA was largely uncharacterized (Morsy, 2018). 
DF caused 50 to 100 million cases, a halfmillion hospitalizations, and 22,000 deaths annually in about 100 countries, with increased 30-fold in last 50 years (WHO, 2017)

\section{Conclusion}

The present data showed that dengue infection affected adults more than children, with male sex predominance. Adults showed the classical manifestations (headache, myalgia, retro-orbital pain), whereas in children showed vomiting and diarrhea as prevalent ones. Thrombocytopenia and elevated liver enzymes were more in adults with severe infection needed prolonged hospitalization.

\section{References}

Abdel-Motagaly, AME, Ibrahim, AMA, Morsy, TA, 2017: An intervention program on blood protozoa acquired by needle stick injury and infection control. J. Egypt. Soc. Parasitol. 47, 2: 309-22.

Al-Azraqi, TA, El Mekki, AA, Mahfouz, AA, 2013: Seroprevalence of dengue virus infection in Aseer and Jizan regions, South-western Saudi Arabia. Trans. R. Soc. Trop. Med. Hyg. trt022

Alhaeli, A, Bahkali, S, Ali, A, Househ, MS, El-Metwally, AA, 2016: The epidemiology of Dengue fever in Saudi Arabia: A systematic review. J. Infect. Publ. Hlth. 9:117-24.

Alwafi, OM, McNabb, SJ, Memish, ZA, Assiri, A, Alzahrani, SH, et al, 2013: Dengue Fever in Makkah, Kingdom of Saudi Arabia, 20082012. Am. J. Res. Commun. 1, 11:123-39.

Arya, SC, Agarwal, N, 2014: Apropos: An update on the incidence of dengue gaining strength in Saudi Arabia and current control approaches for its vector mosquito. Parasit. Vect.7, 1: 233-8

Ayyub, M, Khazindar, AM, Lubbad, EH, Barlas, S, AlfiA, Y, et al, 2006: Characteristics of dengue fever in a large publichospital, Jeddah, Saudi Arabia. J. Ayub Med. Coll. Abbottabad. 18:9-13.

Chen, LH, Wilson, ME, 2004: Transmission of dengue virus without a mosquito vector: nosocomial mucocutaneous transmission and other routes of transmission. Clin. Infect. Dis. 39:e56.

Durand, JP, Couissinier-Paris, P, Tolou, H, 2003: Dengue fever: outbreak in southern Europe? Rev. Prat. 53:1403-6, 1409-10.

El-Badry, AA, El-Beshbishy, HA, Al-Ali, KH, Al-Hejin, AM, El-Sayed, WSM, 2014: Molecular and seroprevalence of importeddengue virus infection in Al-Madinah, Saudi Arabia. Comp. Clin. Pathol. 23, 4:861-8.

Fakeeh, M, Zaki, AM, 2001: Virologic and serologic surveillance fordengue fever in Jeddah, Saudi Arabia, 1994-1999. Am. J. Trop. Med. Hyg. 65:764-7.

Fakeeh, M, Zaki, AM, 2003: Dengue in Jeddah, Saudi Arabia, 1994-2002. Dengue Bull. 27: 13-8.

Gamil, MA, Eisa, ZM, Eifan, SA, Al-Sum, B A, 2014: Prevalence of Dengue Fever in Jizan Area, Saudi Arabia. J. Pure Appl. Microbiol. 8, 1:225-31.

Ginsberg, G, Hattis, D, Sonawane, B, Russ, A, Banati, P, et al, 2002: Evaluation of child/adult pharmacokinetic differences from a database derived from the therapeutic drug literature. Toxicol. Sci. 66:185-200.

Gulati, S, Maheshwari, A, 2007: Atypical manifestations of dengue. Trop. Med. Int. Hlth. 12: 1087-95.

Gutiérrez, MD, Zepeda, H, Márquez, R, 2013: Risk factors associated to the epidemic outbreakof dengue virus infection. Rev. Med. Inst. Mex. Seguro Soc. 51:628-34.

Guzman, MG, Kouri, G. Dengue, 2002: An update. Infectious dis-eases. Lancet 2:33-42.

Hammond, SN, Balmaseda, A, Perez, L, Tellez, Y, Saborio, SI, et al, 2005: Differences in dengue severity in infants, children and adults in a 3-year hospital-based study in Nicaragua. Am. Trop. Med, Hyg. 73:1063-71.

Hanafusa, S, Chanyasanha, C, Sujirarat, D, Khuankhunsathid, I, Yaguchi, A, et al, 2008: Clinical features and differences between child and adult dengue infections in Rayong Province, southeast Thailand. Southeast Asian J. Trop. Med. Publ. Hlth 39:252-9.

Horta, MA, Bruniera, R, Ker, F, Catita, C, Ferreira, AP, 2014: Temporal relationship between environmental factors and the occurrence of dengue fever. Int. J. Environ. Hlth Res. 1:11.

Khan, NA, Azhar, EI, El-Fiky, S, Madani, H H, Abuljadial, MA, et al, 2008: Clinical profile and outcome of hospitalized patients during first outbreak of dengue in Makkah, Saudi Arabia. Acta Trop. 105:39-44.

Kholedi, AA, Balubaid, O, Milaat, W, Kabbash, IA, Ibrahim, A, 2012: Factors associated with the spread of dengue fever in Jeddah Governorate, Saudi Arabia. East. Mediterr. Hlth. J. 18:15-23.

Khormi, HM, Kumar, L, 2012: Assessing the 
risk for dengue fever based on socioeconomic and environmental variables in a geographical information system environment. Geospatial Hlth. 6:171-6.

Kittigul, L, Pitakarnjanakul, P, Sujirarat, D, Siripanichgon, K, 2007: The differences of clinical manifestations and laboratory findings in children and adults with dengue virus infection. J. Clin. Virol. 39:76-81.

Knowlton, K, Solomon, G, Rotkin-Ellman, M, 2009: Mosquito-Borne Dengue Fever Threat Spreading in the Americas. NRDC https://www. nrdc.org/policy-library

Kulkarni, MJ, Sarathi, V, Bhalla, V, et al, 2010: Clinico-epidemiological profile of children hospitalized with dengue. Indian J. Pediatr. 77:1103-7.

Kuo, CH, Tai, DI, Chang-Chien, CS, Lan, CK, Chiou, SS, et al, 1992: Liver biochemical tests and dengue fever. Am. J. Trop. Med. Hyg. 47:265-70.

Martinez Vega, R, Phumratanaprapin, W, Phonrat, B, Dhitavat, J, Sutherat M, Choovichian, V, 2016: Differences in liver impairment between adults and children with dengue infection. Am. J. Trop. Med. Hyg. 94, 5:1073-9.

McCallum, JE, 2008: Military medicine from ancient times to the21st century: Dengue fever. California, USA: ABC-CLIO, Inc.

Memish, ZA, Albarrak, A, Almazroa, MA, Al-Omar, I, et al, 2011: Seroprevalence of Alkhurma and other hemorrhagic fever viruses, Saudi Arabia. Emerg. Infect. Dis. 17:2316-8.

Ministry of Health, 2010: Department of Statistics: Health Year Book 2009. Riyadh, KSA: Saudi Ministry of Health, ISSN: 1319-3228.

Morsy, TA, 2018: Aedes aegypti and dengue virus infections. J. Egypt. Soc. Parasitol. (JESP) 48, 1:183-96.

Namvongsa, V, Sirivichayakul, C, Songsithichok, S, Chanthavanich, P, Chokejindachai, W, et al, 2013: Differences in clinical features between children and adults with dengue hemorrhagic fever/dengue shock syndrome. Southeast Asian J. Trop. Med. Publ. Hlth. 44:772-9.

Raza, FA, Rehman, SU, Khalid, R, Ahmad, J, Ashraf, S, et al, 2014: Demographic and clinico-epidemiological features of dengue Fever in Faisalabad, Pakistan. Plos One. 9:e89868.

Rodrigues, MBP, Freire, HBM, Corrêa, PRL, Mendonça, ML, Silva, MRI, et al, 2005: Is it possible to identify dengue in children based on the Ministry of Health criteria for suspected cases? J. Pediatr. (Rio J). 81:209-15

Shahina, W, Nassara, A, Kalkattawia, M, Bokharia, H, 2009: Dengue fever in a tertiary hospital in Makkah, Saudi Arabia. Dengue Bull. 33: 25-32

Sharmin, R, Tabassum, S, Mamun, K, Nessa, A, Jahan, M, 2013: Dengue fever in Dhaka City, Bangladesh. Mymensingh Med. J. 22:781-6.

Souza, LJ, Pessanha, B, Mansur, L, de Souza, L, et al, 2013: Comparison of clinical and laboratory characteristics between children and adults with dengue. Braz. J. Infect. Dis. 17, 1:27-31

Stramer, SL, Linnen, JM, Carrick, JM, et al, 2012: Dengue viremia in blood donors identified by RNA and detection of dengue transfusion transmission during the 2007 dengue outbreak in Puerto Rico. Transfusion 52:1657.

Torres, JR, Liprandi, F, Goncalvez, AP, 2000: Acute parotitis due to dengue virus. Clin. Infect. Dis. 31:28-9.

Velasco, JMS, Alera, MTP, Yil-Cardenas, C A, Dimaano, EM, Jarman, RG, et al, 2014: Demo-graphic, clinical and laboratory findings among adult and pediatric patients hospitalized with dengue in the Philippines. Southeast Asian J. Trop. Med. Publ. Hlth. 45, 2:337-45.

Wang, C, Lee, I, Su, M, et al, 2009: Differences in clinical and laboratory characteristics and disease severity between children and adults with dengue virus infection in Taiwan, 2002. Trans. R. Soc. Trop. Med. Hyg. 103:871-7.

WHO, 2014: Growing threat of viral haemorrhagic fevers in the Eastern Mediterranean Region: a call for action Regional Office for the Eastern Mediterranean. Cairo, Egypt. Available at http:// applications.emro.who.int/docs/ em rc 544_en.pdf?ua=1.

WHO, 2015: Dengue fever-Egypt http://www. who.int/csr/don/12-november-2015-dengue/en WHO, 2016: severe dengue fever. Available at http://www.who.int/denguecontrol/ faq/en/ index2.html

WHO, 2017: Updated questions and answers related to dengue vaccine Dengvaxia ${ }^{\circledR} \&$ its use Yamamoto, Y, Takasaki, T, Yamada, K, Kimura, M, Washizaki, K, et al, 2002: Acute disseminated encephalomyelitis following dengue fever. J. Infect. Chemother. 8:175-7.

Zaki, A, Perera, D, Jahan, SS, Cardosa, MJ, 2008: Phylogeny of dengue viruses circulating in Jeddah, Saudi Arabia: 1994 to 2006. Trop. Med. Int. Hlth. 13, 4:584-92. 